\title{
Moral and scientific boundaries: research ethics on the Thai-Burma border
}

\author{
Michael J Parker
}

\begin{abstract}
The border between Thailand and Burma (Myanmar) is at the forefront of the global battle against malaria, and is an important site for research. The primary reason for this is the fact that it is on the front line in the battle against the development and spread of resistance to antimalarial drugs. That is, it is one of the primary sites of the arms race between the development of new drugs for the treatment of malaria and the evolution of antimalarial resistance in parasites. ${ }^{1}$ The antimalarial resistance developing here is likely to spread elsewhere. So, much is at stake. Globally, up to a million children each year die from malaria and more than half a billion people are affected.
\end{abstract}

Notwithstanding its global importance, this is a context in which the carrying out of research presents a complex cluster of practical ethical difficulties. One reason for this is that the people who live near the border are mostly migrants or refugees from elsewhere in Burma who have moved to the border area to escape conflict and persecution. ${ }^{2}$ There are currently thought to be two million Burmese migrants living in Thailand (about 150000 in refugee camps) and a further million 'internally displaced' inside Burma. The people living in the border area include a very diverse range of different ethnic, religious, political and language groups. The vast majority live in insecure, unsafe conditions and face a number of serious health difficulties including those relating to injuries from mines as well as to malaria and other diseases.

\section{THE LIMITATIONS OF GUIDELINES}

One of the most important practical ethical challenges facing researchers working on the border arises from the fact that the governance environment within which the research takes place is complex

Correspondence to Professor Michael J Parker, Department of Public Health, The Ethox Centre, University of Oxford, Oxford OX3 7LF, UK;

michael.parker@ethox.ox.ac.uk and underdetermining of good practice. Researchers are faced with the challenge of developing models of good practice against a background of multiple and sometimes conflicting forms of guidance. This means that a key practical ethical challenge confronting researchers is how to go about establishing rigorous, transparent procedures for the development of models of good practice and effective practical ethical solutions in the context of guidelines that are frequently contradictory, ambiguous and in need of interpretation.

\section{DEVELOPING GOOD PRACTICE IN CONSENT}

The variety of languages spoken in the region, the range of values and beliefs, and the inevitable constraints on access to education mean that the process of consent and the development of consentrelated materials is a challenge and may require translation between a number of different languages. ${ }^{3}$ The complexity of the scientific terms such as 'genomics' and processes such as data sharing is difficult to convey in meaningful terms. ${ }^{4}$ In addition to issues related to understanding, it may be very difficult for research subjects to refuse to participate in research when it is carried out by a research centre that is also their main provider of healthcare. There may be also issues of competence where people are invited to be involved in research at times of very great distress.

ETHICS AND COMMUNITY ENGAGEMENT Community engagement is increasingly promoted as key to ethical research practice in low-income countries. However, in the context of research settings such as the Thai-Burma border, the achievement of successful and appropriate community engagement itself presents a number of practical and ethical difficulties. ${ }^{5}$ Some of these relate to the question of how the relevant 'community' is to be identified. Given the wide range and diversity of religious, political, language and ethnic groups in the region, the question of what constitutes the community and who may be a community 'representative' is highly likely to be complex and politically sensitive. Against this background, another set of challenges concerns the question of how best to develop procedures and principles of engagement that are effective, fair, accountable and inclusive.

THE RESPONSIBILITIES OF RESEARCHERS Against the background of pressing and often severe health needs and limited healthcare, a key ethical question in this context is going to concern the nature and limits of the responsibilities of researchers and other research actors to migrant and refugee research populations before, during and after research. This is particularly important when the research centre is also the main provider of healthcare. How might solutions to the challenges of delineating and meeting these obligations be achieved in practice against the background of conflicting and multiple guidelines and different views among various stakeholders? These issues will inevitably be particularly difficult to resolve for members of research teams such as health workers, who are also members of the community.

\section{COLLABORATIONS INVOLVING DIVERSE INSTITUTIONS}

Such tensions will also inevitably arise at the institutional level. Much of the research being carried out at the Thai-Burma border takes the form of research collaborations bringing together a large international network of diverse but interdependent forms of expertise. Such research brings together diverse institutions such as government agencies, hospitals, research institutions, research funders, ministries of health, which are likely to have competing interests and concerns. This suggests that one of the ethical challenges in carrying out research is going to be the building of sustainable relationships, shared practices and values, and trust, and development of pragmatic ways of working in the context of significant differences about what is or is not ethical.

\section{CONCLUSIONS}

In this commentary, it has only been possible to highlight a relatively small selection of the ethical issues arising in research in this context. What this selection shows however is that while the carrying out of scientific research on malaria and other health problems 
existing on the Thai-Burma border is hugely important and of global significance, the successful and appropriate completion of such research is likely to require the identification, analysis and addressing of a wide range of significant and complex ethical difficulties and the development of models of good practice on the ground as part of the scientific endeavour. There is a need for more research on these ethical issues and on the development and evaluation of models for the working out of practical effective solutions in this context.

Acknowledgements Michael Parker is a Principal Investigator of the Global Health Bioethics Network, which is a collaboration between the Ethox Centre in
Oxford and partners in South Africa, Kenya, Vietnam, Thailand, and Malawi. It is supported by Wellcome Trust Strategic Award (096527)

Contributors MJP is the sole author of this paper.

Competing interests None.

Provenance and peer review Commissioned; internally peer reviewed.

Received 25 April 2012

Accepted 30 April 2012

Published Online First

21 May 2012

\section{(6) UNLOKKD}

This paper is freely available online under the BMJ Journals unlocked scheme, see http://jme.bmj.com/site/ about/unlocked.xhtml.

J Med Ethics 2012;38:559-560.

doi:10.1136/medethics-2012-100582

\section{REFERENCES}

1. Phyo AP, Nkhoma S, Stepniewska K, et al. Emergence of artemesinin-resistant malaria on the western border of Thailand: a longitudinal study. Lancet. Published Online First: 5 April 2012. doi:10.1016/s0140-6736(12)60484-X

2. Kusakabe K, Pearson R. Transborder migration, social reproduction and economic development: a case study of Burmese women workers in Thailand. International Migration. Published Online First: 2010. doi:10.1111/ j.1468-2435.2010.00630.x

3. Oh S, van der Stouwe M. Education, diversity and inclusion in Burmese refugee camps in Thailand. Comp Educ Rev 2008;52:589-617.

4. de Vries $\mathbf{J}$, Bull $\mathbf{S}$, Duombo 0, et al. Ethical issues in human genomic research in developing countries. BMC Med Ethics 2011;12:5

5. Cheah PY, Lwin KM, Phaiphun L, et al. Community engagement on the Thai-Burmese border: rationale, experience and lessons learnt. Int Health 2010:2:123-9. 